\title{
Fontes e métodos para a cartografia do comércio no SIG geo-histórico de Lyon
}

[ Sources and methods to view the retail business layers of Lyon town's geo-historical GIS

\section{Olivier Chareire ${ }^{\mathrm{I}}$}

Traduzido do francês por Enali De Biaggi e Vanessa Moura de Lacerda Teixeira.

RESUMO - Os almanaques editados nos séculos XIX e XX permitem criar, pelos conteúdos e disponibilidade, layers de localização das atividades comerciais para um Sistema de Informações Geográficas - SIG geo-histórico. Esses dados sociais podem enriquecer o SIG, cuja finalidade seria analisar no tempo longo as evoluções da cidade de Lyon. • PALAVRASCHAVE - Geo-história; cidade; comércio; SIG; geocodificação. · ABSTRACT · Because of their content and availability, the almanacs during the nineteenth and twentieth century allow to realize some location layers of retail activities for a geo-historical GIS. These social data enrich the GIS whose purpose is to help the Lyon town's analysis of evolution on a long period. - KEYWORDS - Geo-history; town; retail; GIS; geocoding.

Recebido em 5 de abril de 2016

Aprovado em 5 de dezembro de 2016

CHAREIRE, Olivier. Fontes e métodos para a cartografia do comércio no SIG geo-histórico de Lyon. Revista do Instituto de Estudos Brasileiros, Brasil, n. 65, p. I45-I58, dez. 2016.

DOI: http://dx.doi.org/Io.II6o6/issn.23I6-90IX.voi65pI45-I58

I Université Jean Moulin Lyon 3 (Lyon, França). 
O SIG geo-histórico coordenado por Bernard Gauthiez e sua equipe da Universidade de Lyon - Jean Moulin é antes de tudo um meio de capitalizar os dados espaciais referentes ao espaço urbano de Lyon.

Os dados são organizados em layers vetoriais temáticos no formato shapefile, utilizando a mesma referência espacial do plano topográfico digital atual da metrópole de Lyon (SUR - Sistema Urbano de Referência da Grande Lyon). No momento de criação de layers, os objetos ou fenômenos que devem ser cartografados são posicionados e desenhados em função desse referencial único, permitindo assim que se descubra os objetos que se sucederam em um mesmo local. A partir de dados sobre edifícios, parcelas e ruas, certo número de layers são criados para descrever a materialidade do espaço urbano entre os séculos XVII e XX. Os layers de objetos materiais são realizados por "método regressivo", o que permite economia de tempo e maior precisão dos contornos. Para criar o layer, esse método usa os objetos de um layer mais recente que não foram alterados no período, enquanto os objetos que sofreram uma transformação são modificados ou desenhados².

A visualização das evoluções espaçotemporais de configurações de objetos coloca em evidência as transformações sucessivas do espaço urbano de Lyon. Como indica Nicolas Jacob-Rousseau3, "o conhecimento dos estados anteriores de um sistema pode ser usado para definir as trajetórias evolutivas e colocar em destaque os efeitos de herança”. A finalidade do sistema é, assim, permitir a análise geo-histórica da cidade em um tempo longo.

O estudo do espaço urbano inclui também os usos sociais da cidade, dos quais o comércio é um componente. Para Jean-Pierre Bondue, "o comércio, pela sua elevada capacidade de resposta às mudanças, aparece como revelador pertinente das mutações e paradoxos que afetam a dinâmica dos territórios, sem que seja o motor das mesmas"4.

2 GAUTHIEZ, Bernard. Lyon en I824-32: un plan de la ville sous forme vecteur d'après le cadastre ancien. Géocarrefour, v. 83/I, 2008.

3 JACOB-ROUSSEAU, Nicolas. Géohistoire/géo-histoire: quelles méthodes pour quel récit?. Géocarrefour, v. 84/4, 2009.

4 BONDUE, Jean-Pierre. Le commerce dans la géographie humaine. Annales de Géographie, t. I09, n. 6II, p. 94-I02. 
Para as atividades comerciais, nosso projeto atual de realização se estende de meados do século XIX ao final do século XX. Esse período se beneficia de um sistema unificado de referência de localizações com base no sistema de numeração local de edifícios, para todas as fontes de documentos, sobre as atividades. A decisão de implementação de tal sistema de numeração de edifícios para Lyon data de I809, e a sua instalação foi feita gradualmente. $\mathrm{O}$ sistema atribuiu todos os números pares de um lado da rua e números ímpares do outro lado5. Essa permanência na organização da numeração nos permite usar o mesmo método de tratamento para criar o layer dos estabelecimentos de comércio ao longo de todo o período de análise.

O próximo passo é discutir as fontes necessárias para o posicionamento e formatação dos dados, bem como as transformações dos mesmos para gerar os layers.

\section{AS FONTES SOBRE AS ATIVIDADES COMERCIAIS}

Os estudos específicos sobre o comércio urbano que descrevem as atividades e a localização dos estabelecimentos comerciais se desenvolveram bastante a partir das décadas de I960 e I970. No nível intraurbano, essas pesquisas estão frequentemente relacionadas com preocupações de planejamento ou urbanismo comercial. Esse é o caso na Inglaterra, com o trabalho de R. Davies ${ }^{6}$, e na Bélgica, com os trabalhos de A. Sporck 7 .

Geógrafos de língua francesa adotaram e adaptaram os métodos apresentados por A. Sporck, que favorecem o trabalho de campo para reunir as atividades e características dos pontos de venda. Só a investigação de campo permite um verdadeiro cadastro comercial que identifique as características físicas de estabelecimentos locais (área, comprimento e estado da fachada comercial). Ela também ajuda a levantar de forma detalhada a atividade do estabelecimento. As listas compiladas a partir dessas pesquisas são mais detalhadas e mais relevantes do que as classificações utilizadas pelos registros administrativos para fins fiscais (de patente, do imposto profissional) ou para as câmaras de comércio. Na ausência de levantamentos de campo antigos, a realização da cartografia dos estabelecimentos comerciais do passado só pode ser feita graças ao uso de arquivos administrativos ou comerciais.

O estudo do comércio para a formação de um layer no SIG geo-histórico necessita da disponibilidade de fontes sobre os estabelecimentos comerciais existentes, incluindo, pelo menos, uma descrição da sua atividade e de seu endereço para permitir a localização. Se o objeto de estudo também inclui um componente social

5 Esse sistema integra também uma numeração contínua para as docas e para as praças. Mas, às vezes, as praças não contam com uma numeração específica, sendo usada a numeração das ruas que as delimitam.

6 DAVIES, R. L. Marketing geography with special reference to retailing. Cambridge: Retailing and Planning Association, I976, $300 \mathrm{p}$.

7 SPORCK, J. A. Étude de la localisation du commerce de détail. Aspects méthodologiques. Bulletin de la Société Belge d’Études Géographiques, t. XXXIII, I, I964, p. 53-I06. 
que ajude a seguir a vida corporativa do comerciante, então esse dado deve também estar presente na fonte.

O estudo da localização das atividades comerciais para os períodos mais recentes é muito facilitado pelo acesso aos dados digitais, como as bases nacionais de estabelecimentos exercendo uma atividade na França: o arquivo "Sirene”, criado em I973 e gerido pelo Institut National de la Statistique et des Études Économiques - INSEE. Nas décadas de I980-I990, a informatização e o aumento da confiabilidade dos arquivos consulares das Câmaras de Comércio e Indústria e da Câmara de "Métiers" (artesanato) também contribuem para a evolução do registro de empresas e de estabelecimentos, além de facilitar as pesquisas.

Para períodos anteriores, é preciso verificar e digitalizar as informações de outras fontes: anuários de atividades, arquivos de contribuições fiscais e arquivos do registro comercial e de sociedades.

Essas três fontes, indicando a localização do estabelecimento através do seu endereço, podem ser usadas para formar dados integrados em um sistema de informação geográfica.

\section{Os anuários de atividades}

Os anuários ou indicadores são os herdeiros dos almanaques que foram publicados em Lyon desde I7II. Publicados anualmente por editores privados, foram financiados também pelas autoridades locais no período monárquico e na terceira república. Seu conteúdo evoluiu, e eles se tornaram verdadeiros anuários na primeira metade do século XIX. Além das descrições das organizações administrativas, judiciais e religiosas, bem como a lista de serviços com os nomes de seus responsáveis, acrescentou-se a lista de profissões e produtos. Durante a segunda metade do século XIX, a lista dos estabelecimentos e produtos por profissões funciona como uma lista dos "principais habitantes" classificados por ruas e números dos imóveis. A primeira metade do século XX viu o surgimento de listas de assinantes de telefone. Esses anuários propõem uma riqueza de informações que vai além dos domínios do comércio e das atividades comerciais.

Os anuários de I800 até I867 mudaram várias vezes de nome, de editor e de denominação ${ }^{8}$. Três anuários cobrem grande parte do nosso período de estudo: o Annuaire Fournier, de I867-I969, e o Indicateur Labaume, de I86I-I88I, e seu sucessor, o Indicateur Henry, de I88I-I9729 ${ }^{9}$, cujo conteúdo é bastante similar no que diz respeito às principais seções. Esses anuários concorrentes utilizam fontes disponibilizadas pelas administrações municipais a partir de documentos fiscais e censos de população. Uma decisão do tribunal de I870, nos seus considerandos, indica a utilização de tais fontes administrativas. A decisão rejeita a acusação de falsificação feita pelo

8 Os editores são: de I80I a I822, Ballanche, com ou sem sócios; de I823 a I836, Russand; em I837-I838, Lesne e Crozet; de I838 a I840 Pelagaud; de I84I a I876, Mougin e Russand; de I86I a I883, Labaume. Somente a partir de I838 que o termo "anuário" ou “indicateur" substitui o termo "almanaque".

9 Essas denominações não correspondem aos títulos das publicações, que mudaram diversas vezes ao longo do período de estudo. 
editor Labaume, no que diz respeito à publicação da lista dos principais habitantes categorizados por rua, contra o editor Fournier ${ }^{\mathrm{IO}}$.

O anuário se torna mais amplo gradualmente, adicionando novas seções, introduzindo encartes publicitários, especialmente, pelo crescimento do número de estabelecimentos e moradores da cidade. Em I867, ele compreende mais de 860 páginas e, em I937, mais de 2.800. Nos anos I950-I960 foi publicado em dois volumes.

A lista dos principais habitantes por rua é particularmente adequada para o estudo de uma rua, setor ou de toda a área da cidade de Lyon. Essa é a lista que foi estudada para I900 na área da margem direita do Rhône ${ }^{\text {II }}$. A lista está em ordem de nomes de ruas e números dos imóveis, finalmente, por ordem de andar (de baixo para cima) no imóvel, sem que indicações de andar apareçam. Ela também distingue os diferentes imóveis no mesmo endereço, particularmente os que se situam no pátio interno. Ela contém: o sobrenome da pessoa ou o nome da empresa com, nesse caso, o nome de seu dirigente local. Muitas vezes a primeira inicial do nome é mencionada, mais raramente o primeiro nome na íntegra. Finalmente, a atividade ou profissão é sempre indicada.

Durante a utilização da lista deve-se distinguir o lugar de negócio e de residência. A distinção é fácil de se estabelecer para o comércio e muito menos clara para outras atividades, especialmente para as pequenas empresas artesanais, que podem ser feitas no domicílio, entre as quais se encontram várias atividades femininas relacionadas à confecção têxtil, particularmente presentes em Lyon: rendeira, bordadeira ... A posição na lista para o imóvel normalmente determina o local de atividades. Para os profissionais liberais e comerciantes, quando há uma confusão, nota-se a abreviatura "app" para apartamento. Às vezes algumas informações sobre a natureza das instalações são indicadas por abreviaturas (fábrica, oficina, escritório, anexo).

As listas de profissões e produtos estão em ordem alfabética dos itens e, em seguida, em ordem alfabética de sobrenomes ou nome da empresa, para as empresas. Além do nome do proprietário ou dos dirigentes locais de empresas, consta o endereço do estabelecimento. Ela contém uma nomenclatura para Lyon, com cerca de 500 profissões/produtos em I867, passando para I.400 profissões/produtos em I937. Um mesmo estabelecimento, segundo suas atividades, pode ser introduzido em diversas categorias. A lista pode ser usada para produzir estatísticas por atividade ou para o mapeamento, permitindo também, através do cruzamento de informações, levantar incertezas da lista dos "principais habitantes", como a distinção entre o local de trabalho ou domicílio. Com o tempo ele foi incorporando mais e mais anúncios publicitários, principal fonte de financiamento da publicação.

Io ARRÊT du 24 mars I870. Recueil périodique et critique de jurisprudence de législation et de doctrine, année I870, éditeur Dalloz.

II A lista foi filtrada, para manter somente as atividades, sendo relançada por Louis Dufier. DUFIER, Louis. Etat artisanal, commercial, industriel et agricole de Lyon et Villeurbanne en I900. Lyon: Belier, 2003, 353 p. 


\begin{tabular}{|lc|}
\hline \multicolumn{1}{|c|}{ ANNUAIRE FOURNIER DE LYON E DO RHÔNE DE 1937} \\
ITENS/SEÇÕES & NÚMERO DE PÁGINAS \\
- TABELAS GERAIS & 8 PÁGINAS \\
& \\
LYON VILLEURBANNE & \\
- NOMENCLATURA DE RUAS & $25 \mathrm{P}$. \\
- PRINCIPAIS HABITANTES, POR RUA & $665 \mathrm{P}$. \\
- PRINCIPAIS HABITANTES, LISTA ALFABÉTICA & $828 \mathrm{P}$. \\
- COMERCIANTES E INDUSTRIAIS, & \\
POR PROFISSÃO/PRODUTOS (COM PROPAGANDAS) & $831 \mathrm{P}$. \\
DEPARTAMENTO DO RHONE & \\
- ANUÁRIO DAS COMUNAS: & \\
GEOGRAFIA, POLÍTICA, & $108 \mathrm{P}$. \\
COMERCIANTES E INDUSTRIAIS, POR PROFISSÃO & \\
PRINCIPAIS PROPRIETÁRIOS & \\
- PARTE ADMINISTRATIVA & \\
DEPARTAMENTAL, MUNICIPAL PARA LYON, & \\
ADMINISTRAÇÃO GERAL (COMÉRCIO, RELIGIÃO, \\
FINANÇAS, GUERRA, INSTRUÇÃO PÚBLICA, JUSTIÇA, \\
CORREIOS TELÉGRAFOS, OBRAS PÚBLICAS) \\
- ANUÁRIO TELEFÔNICO DO DEPARTAMENTO \\
\hline
\end{tabular}

Figura I - Exemplo de lista de conteúdos do Anuário Fournier nos Arquivos Municipais de Lyon. Fonte: AML

A lista ordenada por ordem de sobrenomes é interessante para genealogistas ou para estudos sobre a origem geográfica da população.

Os Arquivos Municipais de Lyon $(\mathrm{AML})^{\mathrm{I2}}$ têm uma coleção quase completa dos anuários Henry e Fournier. Os livros não estão disponíveis diretamente - a consulta é realizada por microfilme de baixa qualidade, o que dificulta a leitura ${ }^{\mathrm{I3}}$.

Pode-se consultar igualmente os anuários originais na Biblioteca Municipal de Lyon (BML), mas as coleções são incompletas: para o Anuário Fournier existem 33 anos dos Io2 de produção; para o Indicador Henry, 5I de 9I. As coleções da BML dizem respeito, principalmente, ao século XX. Antes de I900 apenas onze anos estão disponíveis para ambos os diretórios ${ }^{14}$. Os Arquivos Departamentais do Rhône (ADR) possuem uma coleção completa do Indicador Henry, de I884-I925, que permite superar as deficiências da Biblioteca Municipal. Também é possível comprar anuários dos séculos XIX ou XX através de sites de livros usados.

Em Lyon, graças à disponibilidade de anuários para várias datas pode-se seguir, de maneira gradual, a evolução do comércio e de outras atividades. Do mesmo modo, os dados impressos e formatados em colunas são mais fáceis de ler do que as fontes fiscais manuscritas.

I2 AML - Archives Municipales de Lyon. Disponível em: <http://www.archives-lyon.fr/archives/sections/fr/ archives_en_ligne>. Acesso em: jan. 2016.

I3 Os microfilmes dos anuários e indicadores podem ser consultados na sala de leitura dos AML.

I4 Referência 950388 para o Anuário Fournier e 950389 para o Indicador Henry. 


\section{A Patente}

A Patente é um imposto nacional francês cuja cobrança ocorreu de I79I a I924.É um imposto devido pelas empresas comerciais, de serviços e de produção. Após I9I4, ele se torna um imposto local e é substituído em I979 pela taxa profissional. Ao longo do tempo foi modificado diversas vezes, interpretado de maneira variada e colocado em questão. No entanto, a estrutura geral de tributação permaneceu semelhante durante o século XIX ${ }^{15}$.

\section{ESTRUTURA DE TRIBUTAÇÃO DA PATENTE}

O IMPOSTO É COMPOSTO DE UM DIREITO FIXO E DE UM DIREITO PROPORCIONAL.

\section{O DIREITO FIXO:}

- DIZ RESPEITO ÀS PROFISSÕES QUE SÃO OBJETO DE UMA CLASSIFICAÇÃO;

- SERVE DE BASE A UMA TRIBUTAÇÃo INVARIÁVEL PARA TODAS AS EMPRESAS DE MESMA ATIVIDADE.

\section{O DIREITO PROPORCIONAL}

- É FIXADO DE ACORDO COM O VALOR DE LOCAÇÃO DO IMÓVEL PROFISSIONAL DO PATENTEADO;

- PODE TAMBÉM SER FIXADO SOBRE O VALOR DE LOCAÇÃO DE DETERMINADOS INSTRUMENTOS DE PRO-

DUÇÃO DA LOJA OU DO ATELIÊ.

A AVALIAÇÃO DO DIREITO PROPORCIONAL VARIA:

- PARA OS ESTABELECIMENTOS DE COMÉRCIO DE ACORDO COM A IMPORTÂNCIA DA LOCALIZAÇÃO;

- PARA AS FÁbRICAS DE ACORDO COM A IMPORTÂNCIA DE UMA PRODUÇão ONDE O RAIO DE VENDA É

AVALIADO ATRAVÉS DOS INSTRUMENTOS IMPLANTADOS.

Figura 2 - Desdobramentos da estrutura de tributação da Patente. Fonte: elaboração do autor

A matriz das contribuições da Patente se apresenta sob a forma de grandes tabelas onde as notas estão manuscritas. A matriz está classificada geograficamente por rua e número do imóvel, sendo, portanto, bem adaptada à constituição de uma base de dados geolocalizada. Essa fonte, como instrumento do sistema tributário, possui um bom nível de confiabilidade.

Além das informações que identificam os proprietários ou as sociedades, os valores dos direitos proporcionais permitem introduzir certa hierarquização da importância das atividades que os almanaques não oferecem. Para explorá-los, é preciso, contudo, levar em consideração as taxas de tributação fixadas em função da nomenclatura das atividades. Eles permitem também distinguir os estabelecimentos ou atividades e residências associados.

A análise das mudanças entre as nomenclaturas de atividades de I844 e de I88I é interessante para o estudo sobre as mutações dos tipos de comércio.

A fonte está disponível nos Arquivos Municipais de Lyon, mas falta o período

I5 Para uma visão resumida sobre a Patente, consultar: MINISTÈRE DE L’ÉCONOMIE ET DES FINANCES. Le Portail de l'Économie et des Finances. Centre des Archives Économiques et Financières - Caef. Disponível em: 〈http://www.economie.gouv.fr/caef/patente\#codification\%20de\%20I944〉. Acesso em: I6 jan. 20I6. Para se aprofundar a respeito do histórico do imposto, consultar: TARDIEU, J. Traité théorique et pratique des patentes. Paris: Larose, I902, 258 p. 
de I880 a I935, em que a taxa profissional que a sucedeu está só parcialmente $\operatorname{arquivada}^{\mathrm{I6}}$.

\section{O registro do comércio e das sociedades (RCS)}

O registro do comércio e das sociedades é uma herança do direito alemão em vigor na Alsácia e Lorraine. Esse sistema, mantido pela Secretaria do Tribunal do Comércio, é introduzido na legislação francesa após a guerra, em I9I9. Diversos estudos sobre a utilização dessa fonte foram publicados ${ }^{\mathrm{I}}$.

Encontramos inscritas no RCS:

- as criações de estabelecimentos comerciais e de sociedades, mas a partir de I936 os artesãos serão inscritos no Registro das Profissões;

- as modificações que os afetam: aumento ou redução de capital, mudança de administrador, acréscimo de nova unidade;

- as exclusões.

O RCS é composto, na realidade, de diversos elementos:

- declarações para fins de inscrição: uma distinção é realizada entre as empresas individuais e as sociedades;

- declarações para fins de inscrições que se modificam;

- registro cronológico;

- registro analítico, que é a síntese da história jurídica da empresa;

- registro alfabético, que permite acessar diretamente as fichas de inscrições.

Essa fonte permite retraçar a história das empresas e a localização de seus estabelecimentos. Devido à sua estrutura, ela é demasiado longa para estudar as unidades espaciais que ultrapassem uma rua. É, portanto, uma fonte complementar para realizar focos localizados e seguir a história de algumas empresas.

O historiador Hervé Joly ${ }^{\mathrm{I} 8}$ insiste no caráter “problemático” dessa fonte devido à heterogeneidade das leituras e do caráter incompleto dos arquivos disponíveis. Um estudo de J. C. Bonnet sobre os comerciantes estrangeiros em Lyon no período entre as duas guerras utiliza o registro do comércio ${ }^{\mathrm{I}}$.

I6 Nos Arquivos Municipais, as patentes do município de Lyon estão na série 3Io WP para o período de I79I a I880 e a série 920 WP para o período I935-I965. O inventário dos pagamentos de I997 menciona a taxa profissional de I973 a I983 unicamente para a sétima região administrativa de Lyon.

I7 ZALC, Claire. L'analyse d'une institution: le registre du commerce et les étrangers dans l'entre-deux-guerres. Genèses, 3I, I998, p. 99-II8.

I8 JOLY, Hervé. L'exploitation des actes de sociétés pour l'histoire des entreprises: intérêts et difficultés. Entreprises et histoire, éditeur Eska, 2003, p. I20-I26.

I9 BONNET, J. C. Étude des petits commerçants étrangers dans l'agglomération Lyonnaise (I9I9-I939) à partir du registre du commerce. Bulletin du centre d'histoire économique et sociale de Lyon, I975. 


\section{O registro dos dados e a sua formatação}

Esse registro foi escolhido para levantar a natureza da atividade comercial tal como ela é apresentada nos almanaques a fim de preservar a possibilidade de pesquisar as atividades específicas. Como exemplo, para as atividades em I900, as pesquisas efetuadas a partir da retranscrição do almanaque por Louis Dufier contabilizavam 788 denominações de atividades/profissões, das quais 301 eram para o comércio.

A delimitação do campo do comércio necessita de um conhecimento acerca das antigas denominações das atividades comerciais. Algumas são suficientemente familiares e não causam problemas, como os "comerciantes de óculos", que são hoje as ópticas. Outros, como o "régrattier", são desconhecidos. No século XIX, o "régrattier" era um comerciante de coisas usadas. O dono de uma mercearia dita "régrattier", além de alimentos, vendia outros produtos em pequenas quantidades: carvão, madeira para aquecimento... O portal da internet do Centre National de Ressources Textuelles et Lexicales (CNTRL) ${ }^{20}$ oferece uma potente ferramenta para as pesquisas sobre as antigas denominações de atividades. Onde colocar os limites do campo do comércio? Um número importante de atividades no século XIX reúne a fabricação e a venda em um quiosque, por exemplo, o sapateiro, o alfaiate... Ao longo do século, os quiosques se transformaram em lojas dedicadas à venda e, em seguida, a loja evoluiu para os magazines, caracterizados pela importância dos bens expostos em vitrines. Os critérios de inclusão no campo do comércio são para essas atividades mistas (produção-venda): uma produção artesanal para o serviço da população residente e uma localização frequente no andar térreo dos imóveis. Esse segundo critério é avaliado a partir das listas por rua dos principais habitantes publicadas nos almanaques.

A utilização dos dados comerciais não pode ser considerada sobre um grande número de categoriais, muitas das quais só agrupam alguns estabelecimentos. Utilizamos, para uma primeira apresentação, a nomenclatura estabelecida pela Comissão Francesa de Geografia do Comércio baseada nos grupos destinados aos bens e serviços (alimentares, equipamento pessoal, equipamento residencial). Os estabelecimentos comerciais foram classificados em 35 categorias de atividades que se agrupam em oito classes. Outras classificações baseadas nos modos de frequentação e nos fatores de localização formam uma grade de estudo mais pertinente ao espaço comercial urbano ${ }^{21}$. A evolução dos tipos de atividades comerciais e dos modos de consumo dos habitantes durante um século deve ser levada em conta para constituir categorias representativas da organização socio espacial da cidade. Análises das afinidades de localização das atividades em diferentes épocas deveriam auxiliar na determinação dos agrupamentos dessas últimas.

20 CNRTL - Centre National de Ressources Textuelles et Lexicales (Centro Nacional de Recursos Textuais e Lexicais). A gestão do portal é realizada por UMR ATILF (CNRS - Université de Nancy). Disponível em: <http:// www.cnrtl.fr/lexiques $>$. Acesso em: out. 2016.

2I GRIMMEAU, Jean-Pierre. Affinités spatiale et facteurs de localisation des types de commerces de détail dans la ville. Recherches de géographie urbaine, Hommage à J.A.Sporck, éditeur Société de Géographie de Liège, I987, p.30I-3I6 
As pesquisas dos documentos-fontes manuscritos, apresentadas frequentemente em grandes tabelas, só podem ser realizadas através de elaboração de planilha. Para os documentos impressos de boa qualidade podemos utilizar as ferramentas de reconhecimento de caracteres para produzir o texto. Os documentos da segunda metade do século XX são adaptados a esses tratamentos. É necessário, em seguida, reformatá-los sob a forma de tabela. Os almanaques impressos em papel de baixa qualidade não permitem aos programas de reconhecimento de caracteres produzir bons resultados. O texto gerado apresenta muitos erros, e o tempo de correção associado à reformatação ultrapassa aquele usado para a captura direta pelo teclado.

\section{Dos DADOS Às CAMADAS Do SIG}

\section{Os dados pela geocodificação}

A geocodificação posiciona os estabelecimentos comerciais no espaço mapeado. Para isso, é necessário obter os dados espacializados com o nome das ruas e a numeração dos edifícios. As sucessões de regimes políticos (II República/II Império/III República) e o costume desde o início da III República de honrar os homens célebres multiplicaram as modificações dos nomes das ruas. Maurice Vanario ${ }^{22}$ os levantou, e sua obra é um guia precioso para preparar o trabalho de geocodificação. Através do trabalho de Vanario, a fim de facilitar a pesquisa dos nomes antigos e de sua correspondência atual, criamos uma base de dados sobre as modificações dos nomes das vias. $\mathrm{O}$ trabalho em elaboração contém atualmente dois terços das modificações.

Quando a modificação de uma denominação só diz respeito a uma parte de uma via, isso leva a uma modificação da numeração dos edifícios. Uma bifurcação prolongando uma rua, se ela se situa do lado do início da rua, induz igualmente uma renumeração. Essa variação dos nomes e numerações obriga a conhecer e trabalhar os dados de endereços correspondendo, ao máximo, à data dos registros dos estabelecimentos.

Para Lyon, as antigas plantas topográficas da cidade indicam a numeração dos edifícios. Elas estão disponíveis no site dos Arquivos Municipais ${ }^{23}$. Existem duas séries, sendo a mais detalhada aquela na escala I:500 em 604 folhas para o período de I86I a I983. Essa série contém também o nome do proprietário das parcelas, o que representa um dado útil para os estudos sociais acerca das relações propriedades/ atividades. Outra série na escala I:2.000 está também disponível e cobre o território do munícipio em 35 folhas para o período de I920 a I983. Para algumas folhas, a primeira edição é de I9IO ${ }^{24}$. As folhas mais antigas cobrem o centro da cidade, e as edições da periferia são mais recentes e se sobrepõem à evolução da expansão da

22 VANARIO, Maurice. Rues de Lyon à travers les siècles: XIVe-XXIe siècles. Direction de Henri Hours. 2. ed. Lyon: Editions Lyonnaises d'Art et d'Histoire, 2002, 333 p.

23 AML, op. cit.

24 AML: série 4s para a cobertura na escala I:500 e série 5s para a cobertura na escala I:2.000. 
urbanização. Para as duas escalas, as datas das edições sucessivas diferem de uma folha a outra, e não existe cobertura de dados completa numa data determinada. Apesar das imprecisões sobre a periodização das modificações, essas séries de mapas são práticas para investigar as mudanças das denominações e numeração das ruas. As decisões municipais que dizem respeito às vias permitem também seguir essas modificações. Elas estão arquivadas em diversas pastas dos Arquivos Municipais de Lyon $^{25}$.

É preciso também notar que as localizações criadas a partir do endereço postal não oferecem a possibilidade de produzir um cadastro comercial, como podemos perceber a partir dos levantamentos de campo. De fato, os imóveis lioneses construídos desde o final do século XVIII possuem geralmente uma fachada bastante longa sobre a rua, contendo muitas vezes diversas células comerciais. Assim, o endereço não permite reconstituir, para os imóveis, a sequência de localizações ao longo da rua. Da mesma forma, as localizações geradas a partir dos endereços não podem reconstituir a evolução das atividades de uma área comercial.

\section{Procedimentos de geocodificação}

A geocodificação se realiza de maneira manual ou automatizada.

O procedimento manual utiliza a referência da posição dos endereços nas plantas antigas que contêm os nomes das vias e a numeração dos imóveis. Essas plantas são georreferenciadas em relação ao plano topográfico atual da metrópole da Grande Lyon.

Os procedimentos automatizados de geocodificação utilizam uma base cartográfica de endereços, que pode ser organizada sob a forma de "pontos-endereço" ou sob a forma de segmentos de ruas contendo os endereços de início e fim do segmento para os dois lados da via. Os segmentos são delimitados por dois cruzamentos sucessivos. Com a primeira forma o ponto mapeado é situado no polígono do desenho do imóvel ou do lote, permitindo associar a informação comercial e parcelar à edificação. Tecnicamente, o procedimento se realiza por uma simples união dos endereços comerciais com a camada de pontos-endereço. Com uma base por segmento de via, a geolocalização se realiza pela interpolação, utilizando um módulo específico de tratamento chamado "geocodificador". O posicionamento cartográfico é assim menos preciso e não pode estar associado com precisão a um edifício ou a um lote. A imprecisão é insignificante quando visualizamos um conjunto extenso em pequena escala. Pode ser desvantajoso para escalas maiores, como, por exemplo, no estudo de um bairro ou de uma rua, em que a referência espacial é baseada no imóvel. O principal inconveniente desse procedimento é a

25 As pastas dos AML contendo as informações sobre a denominação e a numeração das vias são: 323 WP para o período I792-I9I2; e 944 WP para o período I9OI-I9I2. As pastas 32I WP, 330 WP, 33I WP, 452 WP, 950 WP, 95I WP, 955 WP contêm informações sobre as criações, alargamentos e prolongamentos de vias, úteis para situar as mudanças. 
impossibilidade de associar de maneira confiável dados sociais e dados urbanos (edifícios e lotes) não permitindo o enriquecimento dos dados por cruzamento.

A geocodificação por pontos-endereço é preferível, e a realização de uma camada com pontos-endereço exige muito tempo. Para que a automatização da geocodificação seja eficaz, é preciso que a camada dos pontos-endereço seja completa. O número de pontos a criar pode assim ultrapassar bastante o número de estabelecimentos comerciais a geocodificar, eliminando o ganho de tempo da automatização do tratamento.

Para geocodificar os dados de I867 e de I900 da área do centro da cidade entre as praças Terreaux e Bellecour, duas bases de pontos-endereço foram realizadas utilizando os planos topográficos de duas épocas. A base de 1867 foi produzida a partir da base de I900, pelo método regressivo. Para o centro da cidade, as mudanças na denominação e numeração das vias são pouco numerosas entre essas duas datas.

A camada dos estabelecimentos de comércio de Lyon no conjunto da margem direita do Rhône foi produzida a partir de uma base de geocodificação adaptada à época, por segmento de rua. Essa base é derivada de uma base dos segmentos realizada para o período de 1995 de acordo com o método regressivo (figura 3).

\section{Alguns estabelecimentos comerciais de Lyon em 1900}
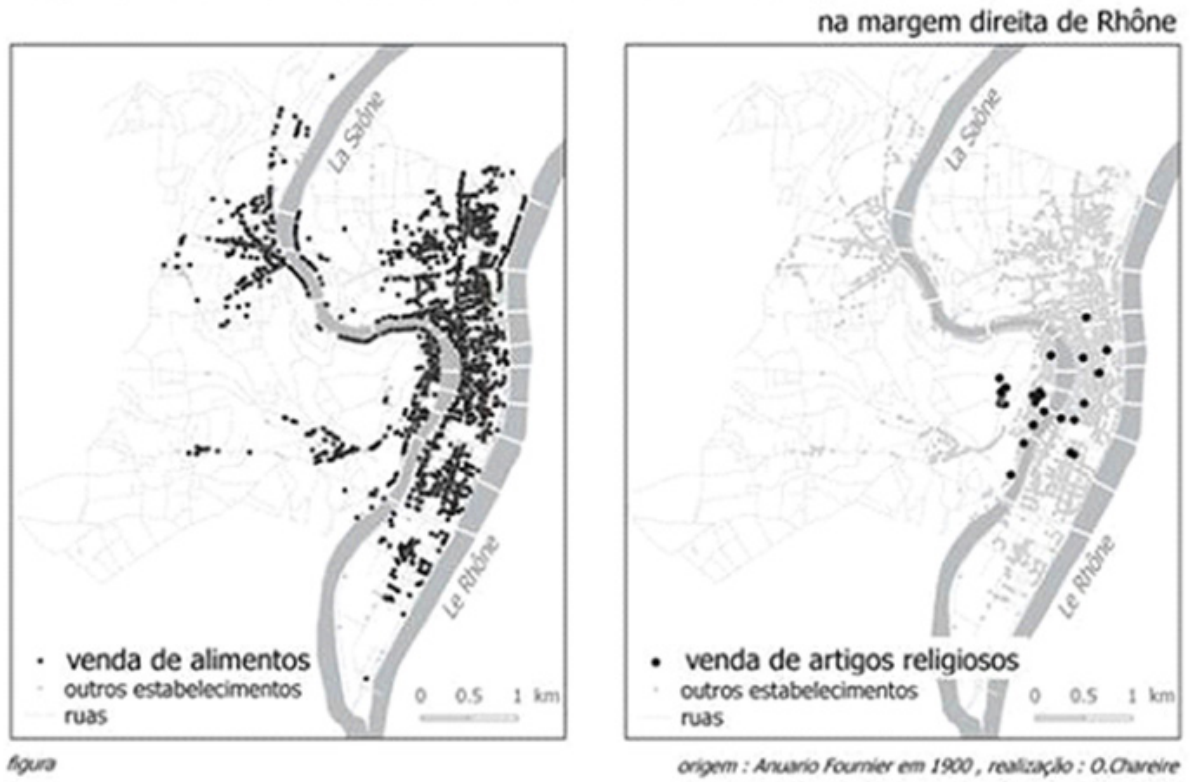

Figura 3 - Alguns estabelecimentos comerciais de Lyon em I900 na margem direita do Rhône. Fonte: Anuário Fournier, I900 


\section{ConClusão}

Das três fontes apresentadas, os almanaques Fournier e Henry sobre Lyon e o Departamento do Rhône são os mais práticos e disponíveis para realizar as camadas de estabelecimentos comerciais no período I860-I970. A exploração dos dados da Patente permitiria enriquecer os dados, hierarquizando a importância dos estabelecimentos. O registro do comércio, pela sua estrutura, não pode ser somente uma fonte pontualmente complementar, já que a sua utilidade é também a de poder reconstituir a história das empresas.

A partir dos endereços dos estabelecimentos utilizando uma base de geocodificação por ponto-endereço, os posicionamentos gerados autorizam um cruzamento, por análise espacial, com os dados cadastrais e aqueles dos imóveis, abrindo assim o campo de estudos dessas relações.

Além do comércio, numerosos dados úteis para o estudo da cidade são encontrados através dos endereços e eles deveriam ser integrados ao SIG geo-histórico de Lyon. A quantidade de dados existentes justificaria a realização de uma ferramenta permitindo uma codificação automatizada, qualquer que fosse o ano dos dados. A constituição, em andamento, de um arquivo das mudanças de denominação das vias é um primeiro elemento da ferramenta. A disponibilidade de uma camada de pontos-endereço no open-data da Metrópole da Grande Lyon oferece outro elemento importante para essa ferramenta. A ferramenta de geocodificação poderia ser realizada a partir dessa camada utilizando as informações das séries de planos topográficos de Lyon e o método regressivo.

SOBRE O AUTOR

OLIVIER CHAREIRE é professor do Département de Géographie et Aménagement du Territoire, Université de Lyon, Université Jean Moulin Lyon 3, CNRS Environnement Ville et Société - UMR 5600.

E-mail: olivier_chareire@yahoo.fr

\section{REFERÊNCIAS BIBLIOGRÁFICAS}

AML - Archives Municipales de Lyon. Disponível em: <http://www.archives-lyon.fr/archives/sections/ fr/archives_en_ligne>. Acesso em: jan. 2016.

ARRÊT du 24 mars I870. Recueil périodique et critique de jurisprudence de législation et de doctrine, année I870, éditeur Dalloz.

BONDUE, Jean-Pierre. Le commerce dans la géographie humaine. Annales de géographie, t. I09, n. 6II, p.

94-IO2. 
BONNET, J. C. Étude des petits commerçants étrangers dans l'agglomération Lyonnaise (I9I9-I939) à partir du registre du commerce. Bulletin du centre d'histoire économique et sociale de Lyon, I975.

CNRTL - Centre National de Ressources Textuelles et Lexicales. Disponível em: <http://www.cnrtl.fr/ lexiques $>$. Acesso em: out. 2016.

DAVIES, R. L. Marketing geography with special reference to retailing. Cambridge: Retailing and Planning Association, I976, $300 \mathrm{p}$.

DUFIER, Louis. Etat artisanal, commercial, industriel et agricole de Lyon et Villeurbanne en I900. Lyon: édition Belier, 2003, $353 \mathrm{p}$.

GAUTHIEZ, Bernard. Lyon en I824-32: un plan de la ville sous forme vecteur d'après le cadastre ancien. Géocarrefour, v. 83/1, 2008.

GRIMMEAU, Jean-Pierre. Affinités spatiale et facteurs de localisation des types de commerces de détail dans la ville. Recherches de géographie urbaine, Hommage à J. A. Sporck, éditeur Société de Géographie de Liège, I987, p. 30I-3I6.

JACOB-ROUSSEAU, Nicolas. Géohistoire/géo-histoire: quelles méthodes pour quel récit?. Géocarrefour, v. 84/4, 2009.

JOLY, Hervé. L’exploitation des actes de sociétés pour l'histoire des entreprises: intérêts et difficultés. Entreprises et histoire, éditeur Eska, 2003, p. I20-I26.

MINISTĖRE DE L'ÉCONOMIE ET DES FINANCES. Le Portail de l'Économie et des Finances. Centre des Archives Économiques et Financières - CAEF. Disponível em: <http://www.economie.gouv.fr/caef/ patente\#codification\%20de\%20I944>. Acesso em: I6 jan. 2016.

SPORCK, J. A. Étude de la localisation du commerce de détail. Aspects méthodologiques. Bulletin de la Société Belge d'Études Géographiques, t. XXXIII, I, I964, p. 53-I06.

TARDIEU, J. Traité théorique et pratique des patentes. Paris: Larose, I902, 258 p.

VANARIO, Maurice. Rues de Lyon à travers les siècles: XIVe-XXIe siècles. Direction de Henri Hours. 2. ed. Lyon: Editions Lyonnaises d'Art et d'Histoire, 2002, 333 p.

ZALC, Claire. L'analyse d'une institution: le registre du commerce et les étrangers dans l'entre-deuxguerres. Genèses, n. 3I, juin I998, p. 99-II8. 